\title{
Corrosion Rate of Black Chromium Coating Result of Electroplating on Copper
}

\author{
Syamsul Hadi ${ }^{1, a}$, Sza Sya Monica Valeria ${ }^{1, b}$, Satworo Adiwidodo ${ }^{1, \mathrm{c}}$, Utsman Syah Amrullah $^{1, d}$, \\ R.N. Akhsanu Takwim, ${ }^{1, e}$, and Hilmi Iman Firmansyah ${ }^{1, f}$
}

\begin{abstract}
${ }^{1}$ Mechanical Engineering Department, State Polytechnic of Malang, Jalan Soekarno-Hatta No. 9, Malang 65141, Indonesia asyamsul.hadi@polinema.ac.id, bszasyamonica@gmail.com, ${ }^{\mathrm{c}}$ satworo.adiwidodo@ polinema.ac.id, dutsman.syah@polinema.ac.id, eakhsanu.takwim@polinema.ac.id, ffirmansyahilmi@polinema.ac.id
\end{abstract}

\begin{abstract}
The problem faced is that the white chromium coating has a low selling value or aesthetic value than the black chromium layer which is more in demand, especially by the younger generation who prioritizes aesthetics. The purpose of the corrosion test was to determine the corrosion resistance ability of the black chromium coating resulting from the electroplating process on the relationship between the solution temperature and the immersion time of copper in a corrosive solution. Corrosion test methods include literature studies, field observations, weighing specimens, immersing specimens in corrosive solutions, weighing specimens, calculating corrosion rates, and data analyzing. Corrosion test results show that the higher the temperature of the solution and the longer the immersion time, the smaller the corrosion rate for the lowest conditions at $30^{\circ} \mathrm{C}$ and a duration of 5 minutes with a corrosion rate of 0.2004 $\mathrm{mm} / \mathrm{year}$ and the highest conditions at a temperature of $50^{\circ} \mathrm{C}$ and a duration of 9 minutes at a rate of corrosion of $0.0108 \mathrm{~mm} / \mathrm{year}$.
\end{abstract}

Keywords: electroplating, temperature,; immersion time, corrosion rate, copper.

\section{Introduction}

The resistance of the black chromium layer resulting from electroplating on copper was measured by corrosive treatment on the resulting coating in the form of a corrosion rate.

Previous studies have examined the effect of the associated parameters on the coating on the electroplating of various coating materials on various specimen materials under various conditions.

Black coatings on metal have been widely used for decorative coatings, solar panels, or optical instruments [1]. Immersion of copper specimens in $\mathrm{NaCl}$ solution at a concentration of $36.05 \mathrm{~g} / \mathrm{l}$ for 336 hours from the results of electroplating at 10,20,30,40, and 50 minutes respectively, obtained a corrosion rate of $0.029,0.013$, $0.017,0.022$, and $0.012 \mathrm{~mm} /$ year, whereas uncoated copper has a corrosion rate of $0.308 \mathrm{~mm} /$ year which means that copper metal coated with nickel-chromium is most effective at resisting corrosion with electroplating time at 50 minutes [2]. Black chromium plating on copper with various trivalent electrolyte solutions and hexavalent electrolytes are good results at $10{ }^{\circ} \mathrm{C}$ electrolyte temperature, current density $55 \mathrm{~A} / \mathrm{dm}^{2}$ [3]. The corrosion resistance of copper-tin alloys depends on the thickness of the Chromium plating and the duration of the test in the corrosion chamber [4]. Electrochemical impedance spectroscopy (EIS) shows that chromium coated A588 steel has better corrosion resistance $\left(\mathrm{E}_{\text {corr }}=-\right.$ $1.742 \mathrm{~V} ; \mathrm{I}_{\text {corr }}=-0.334 \mathrm{~mA}$ ) than $\mathrm{Cu}, \mathrm{Ni}, \mathrm{Zn}$ layers [5]. Chromium electroplating at a duration of 35, 45, and 65 minutes resulted in an average corrosion rate of 0.0236 , 0.0607 , and $0.0135 \mathrm{mpy}$ (mil/year) respectively, which means that the average corrosion rate tends to decrease with the length of coating time [6]. Chromium electroplating at $6,9,12 \mathrm{~V}$ respectively, has a corrosion rate of $0.5781,0.2683,0.0173 \mathrm{~mm} / \mathrm{year}$, and for the uncoated specimens, the corrosion rate reached 3.5052 $\mathrm{mm} /$ year [7]. Electroplating of ST 37 with Nickel and Chromium at the lowest duration of 10 minutes obtained a precipitate of $0.1095 \mathrm{~g}$ and the highest duration was 50 minutes, a precipitate of $0.5475 \mathrm{~g}$ was obtained, the lowest electric current was $0.24 \mathrm{~A}$, the precipitate was $0.1748 \mathrm{~g}$ and the highest electric current was $1.20 \mathrm{~A}$, a precipitate of $0.8592 \mathrm{~g}$ is obtained, which means that the longer the duration and the higher the current, the heavier the precipitate is obtained [8]. Electroplating of ST 40 with Nickel and Chromium at a solution temperature of $40,45,50,55$ and $60^{\circ} \mathrm{C}$ indicates that the increase of the liquid temperature, the thickness and hardness increase, but at $60{ }^{\circ} \mathrm{C}$ the thickness and hardness decrease due to the Chromium ions attached on the surface of the specimen has saturation properties, so it can damage the bond layer of the specimen which 
reduces the surface hardness [9].The thickness of the $\mathrm{Cu}$ layer resulting from electroplating on low carbon steel is influenced by the duration of the process and the current with a value in the current range of $0.1 \div 0.5 \mathrm{~A} / \mathrm{cm}^{2}$ and the duration of the process at 5 minutes, the thickness of $\mathrm{Cu} 0.119 \div 0.521 \mu \mathrm{m}, 10$ minutes, the thickness of $\mathrm{Cu}$ $0.247 \div 0.931 \mu \mathrm{m}, 15$ minutes, the thickness of $\mathrm{Cu} 0.250$ $\div 1.751 \mu \mathrm{m}$, and 20 minutes, the thickness of $\mathrm{Cu} 1.001 \div$ $2.355 \mu \mathrm{m}[10]$.

\section{Research Methodology}

The independent variables were solution temperature and duration of the electroplating process of black chromium, and the dependent variable was the corrosion rate, while the controlled variables were $\mathrm{pH}$ of the solution, the area of contact of the specimen in immersion, and electric voltage.

The flow diagram of the electroplating process of black chromium is shown in Figure 1.

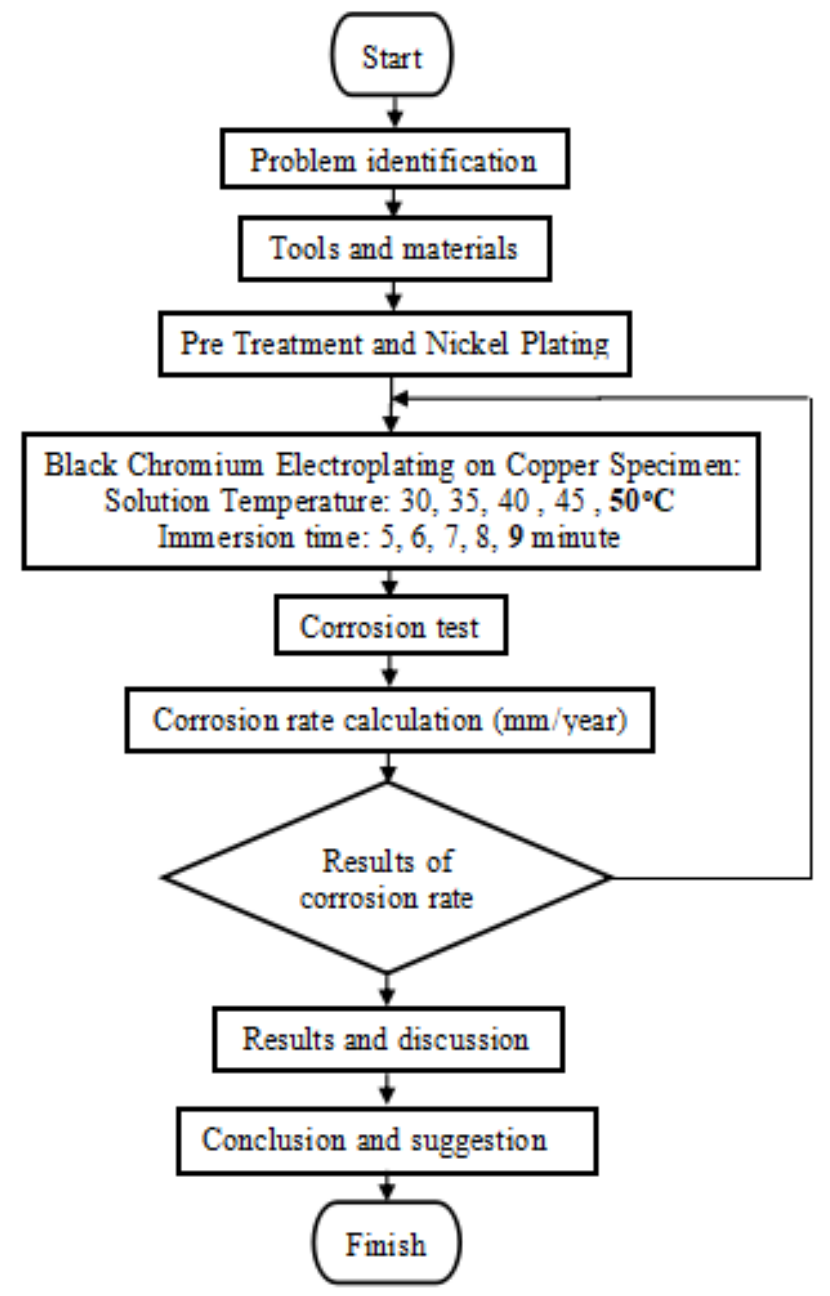

Figure 1. Flow diagram of the electroplating process of black chromium
Copper specimens with dimensions of $50 \times 20 \times 3$ $\mathrm{mm}$ are made of $3 \mathrm{~mm}$ hanger holes that surface is flattened and polished using a sponge grinder [10] is shown in Figure 2.

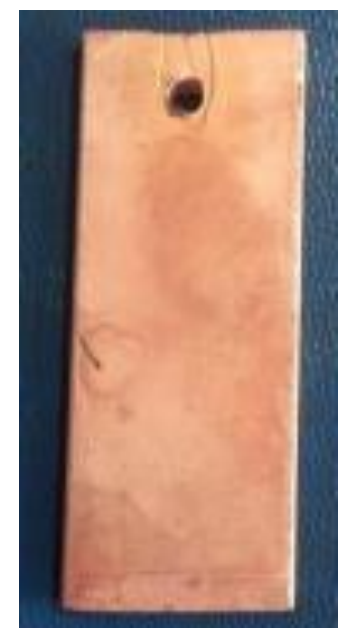

Figure 2. Copper specimen

All specimens were subjected to a treatment process to be cleaned the surface with a metal cleaner and then immersed in an activation solution containing $\mathrm{HCl}$ and aquadest with a ratio of $1: 1$ for 3 minutes at a temperature of $50^{\circ} \mathrm{C}$ is shown in Figure 3 .

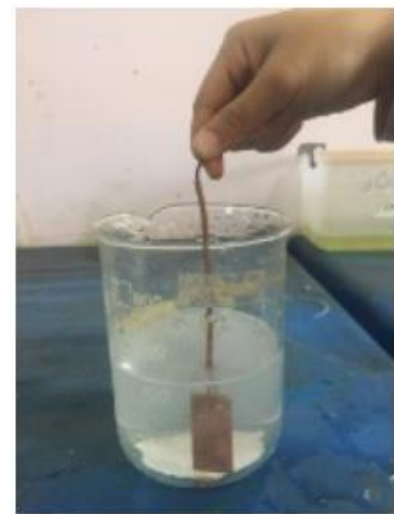

(a)

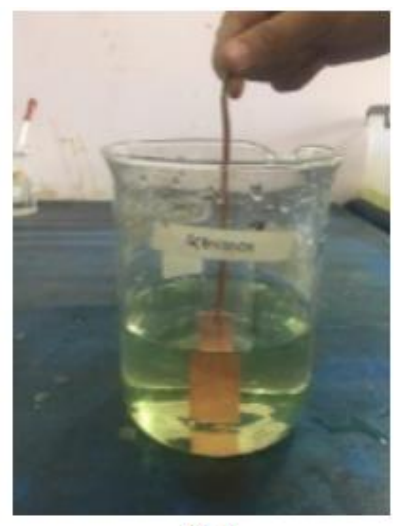

(b)
Figure3. Pretreatment in a solution of (a) metal cleaner, and (b) activation

The electroplating process is divided into 2, namely Nickel plating as the base for gloss color at $40^{\circ} \mathrm{C}$ for 20 minutes and black chromium plating at $50^{\circ} \mathrm{C}$ for 9 minutes is shown in Figure 4. 


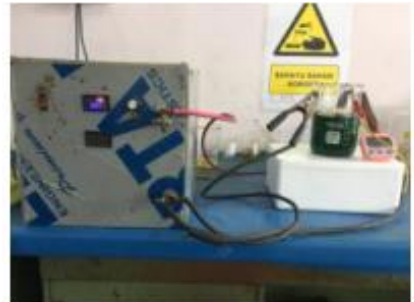

(a)

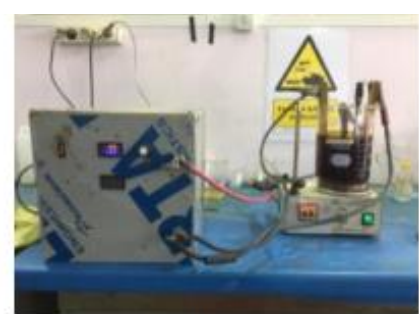

(b)
Figure 4. Electroplating (a) Nickel, and (b) Black Chromium

The best results of electroplating on copper with black chromium are at a temperature of $50^{\circ} \mathrm{C}$ and an immersion time of 9 minutes is shown in Figure 5.

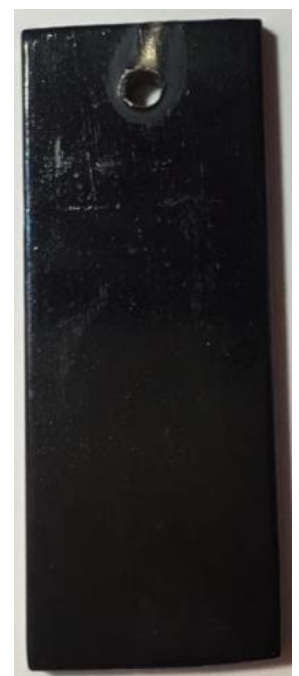

Figure 5. Specimen from the electroplating process of black chromium at $50^{\circ} \mathrm{C}$ for 9 minutes

Corrosion testing of specimens coated with Black Chromium was carried out by immersing them in a $\mathrm{NaCl}$ solution with a concentration close to the $\mathrm{NaCl}$ concentration in seawater at $36.05 \mathrm{~g} / \mathrm{l}$ by immersion for 336 hours ( 2 weeks) which the condition of the solution is the same as that of Dewi and Ahmadi [2] is shown in Figure 6.

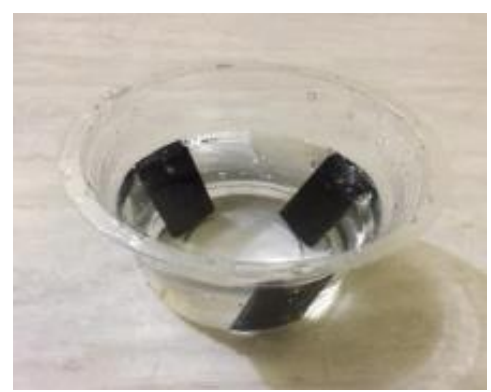

Figure 6. Specimens under corrosion test
The data from the corrosion rate test in the form of the difference in specimen weight before and after corroding which is used by Digital Analytical Scales with an accuracy of one ten thousand grams is shown in Figure 7.

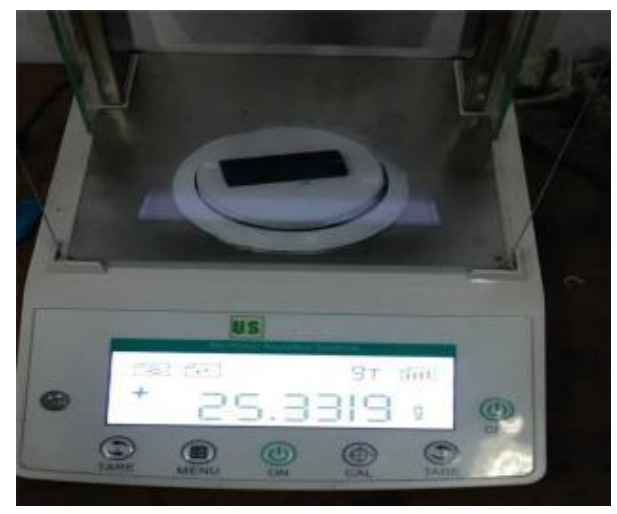

Figure 7.Digital Analytical Scales

One of the methods for determining the corrosion rate is by calculating the weight per unit time or the depth per unit penetration time. The rate of reaction can be expressed in inches per year (ipy), mils per year (mpy), millimetres per year (mmpy), or micrometers per year $(\mu \mathrm{m} / \mathrm{y})[7]$.

The difference in specimen weight is determined by equation (1).

Where:

$$
\Delta \mathrm{W}=\Delta \mathrm{V} \times \rho
$$

$\Delta \mathrm{W}$ : Difference in specimen weight $(\mathrm{g})$

$\Delta \mathrm{V}$ : Difference in specimen volume $\left(\mathrm{mm}^{3}\right)$ $\rho$ : Density of specimen $\left(\mathrm{g} / \mathrm{cm}^{3}\right)$

The depth of penetration on the metal surface is determined by equation (2).

$$
\mathrm{t}=\Delta \mathrm{V} / \mathrm{A}
$$

where:

$\mathrm{t}$ : penetration depth $(\mathrm{mm})$

$\Delta \mathrm{V}$ : difference in specimen volume $\left(\mathrm{mm}^{3}\right)$

A: Surface area $\left(\mathrm{mm}^{2}\right)$

The corrosion rate that occurs is determined by equation (3).

$$
\mathrm{r}=\mathrm{t} / \mathrm{T}
$$

where:

r: Corrosion rate ( $\mathrm{mm} /$ year)

$\mathrm{t}$ : Depth of penetration $(\mathrm{mm})$

T: Time (years) 


\section{Result and Discussion}

The results of calculating the corrosion rate for various solution temperatures and the duration of immersion of the black chromium electroplating specimens in the solution are shown in Table 1 and Figure 8 [11].

Table 1 . The corrosion rate of black chromium coating on copper

\begin{tabular}{|c|c|c|c|c|c|}
\hline \multirow{2}{*}{ Temperature $\left({ }^{\circ} \mathrm{C}\right)$} & \multicolumn{5}{|c}{ Duration of immersion process (Minute) } \\
\cline { 2 - 6 } & 5 & 6 & 7 & 8 & 9 \\
\hline 30 & 0.1811 & 0.1354 & 0.1318 & 0.1259 & 0.1059 \\
\hline 35 & 0.1420 & 0.1184 & 0.1048 & 0.0926 & 0.0812 \\
\hline 40 & 0.1240 & 0.0858 & 0.0676 & 0.0532 & 0.0485 \\
\hline 45 & 0.0881 & 0.0622 & 0.0485 & 0.0403 & 0.0384 \\
\hline 50 & 0.0653 & 0.0404 & 0.0337 & 0.0159 & 0.0100 \\
\hline
\end{tabular}

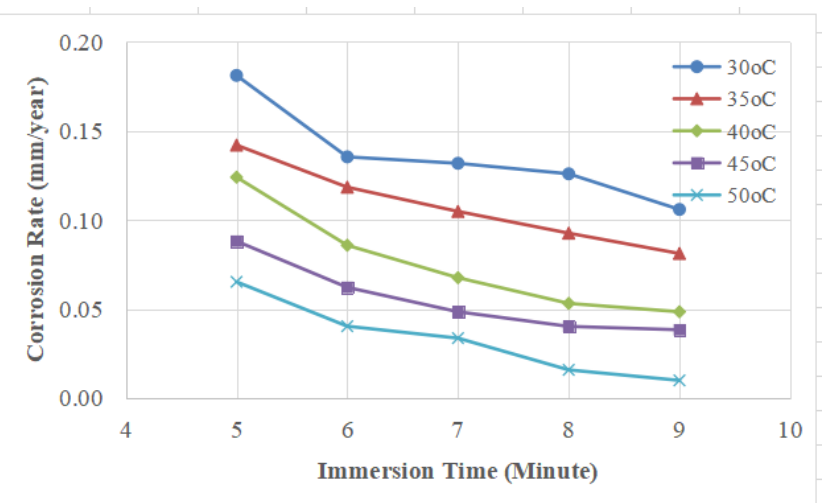

Figure 8. Corrosion rate for various solution temperatures and the duration of immersion of the black chromium electroplating specimens in the $\mathrm{NaCl}$ solution [11]

Figure 8 shows that the higher the temperature of the solution, the lower the corrosion rate of the specimens resulting from black chromium electroplating immersed in $\mathrm{NaCl}$ solution. Likewise, the longer the specimen immersion in $\mathrm{NaCl}$ solution shows a lower corrosion rate, which indicates that the black chromium layer which is longer electroplated has better corrosion resistance.

Dewi and Ahmadi [2] obtained a corrosion rate of $0.029 \mathrm{~mm} /$ year for the duration of the electroplating process for 10 minutes, whereas in this study the results of the corrosion rate were 0.1059 to $0.01 \mathrm{~mm} /$ year for the duration of the process for 9 minutes for a temperature range from 30 to $50^{\circ} \mathrm{C}$. From the comparison of the two results, the corrosion rate shows that the value is included in the value range of this study because the results of Dewi and Ahmadi's research do not state the electroplating temperature.

\section{Conclusion}

The conclusions from the discussion are:

1. The higher the solution temperature in black chromium electroplating, the slower the corrosion rate will be because the higher the temperature produces an even and smoother layer on the surface,

2. The longer the duration of the black chromium electroplating, the slower the corrosion rate will be, because the longer the immersion time, the thicker the black chromium layer is, so the corrosion rate will be slower.

3. In future work, it is better if the research parameters are added in addition to the temperature and time of the solution to determine the corrosion rate, especially those that have significant interaction.

\section{Acknowledgement}

Gratitude is to the Head of Material Treatment Laboratory, Department of Mechanical Engineering, State Polytechnic of Malang for supporting research facilities in the electroplating process of black chromium.

\section{References}

[1] J. Takadoum, "Black coatings: a review," Euro. Phy. J.: App. Phy., EDP Sci., vol. 52, no. 3, pp. 1-15, November 2010.

[2] C. A. Dewi and Ahmadi, "Effect of duration on decorative Chrome electroplating with Copper base metal on corrosion rates," J. of Hydrogen, vol. 1, no. 2, pp. 107-111, 2013.

[3] Sjöberg, J., "Validation and development of an electrodeposition process to deposit a black chromium coating from a trivalent chromium electrolyte," Thesis, Uppsala, Universitet, September 2016.

[4] C. F. Oduoza and S. Hingley, "Electrochemical evaluation of corrosion resistance of chromium plated nickel and copper tin alloys, a comparative study," J. Electrochem. Sci. Eng. 8(3), pp. 227-239. 2018.

[5] J.R. Deepak, V.K.B. Raja, G.S. Kaliaraj, "Mechanical and corrosion behavior of $\mathrm{Cu}, \mathrm{Cr}, \mathrm{Ni}$ and $\mathrm{Zn}$ electroplating on corten A588 steel for scope for betterment in ambient construction applications," Results in Phy., vol. 14, pp. 1-10, June 2019.

[6] M. Santoso, "Corrosion rate of Chrome and Nickel plating by electroplating process on low carbon steel on time variation," Final Project, Faculty of Eng., Pancasakti Univ., Tegal, 2020.

[7] H. Alian, "The effect of stress on the electroplating process of steel with Zinc and Chrome coating on its hardness and corrosion rate," $9^{\text {th }}$ Annual National Seminar on Mech. Eng. (SNTTM), Palembang, MIV-245, 13-15 October 2010.

[8] Ahmadi and B. Holil, "Nickel-chrome electroplating study on ST37 type steel for high school chemistry learning," Proc. of the 2011 National Symposium on Learning and Sci Innovation (SNIPS 2011), Bandung, pp. 230-232, 22-23 June 2011.

[9] S. R. Yulianto and E. Widodo, "Analysis of the effect of variations in Chrome Nickel plating process temperature on the quality of thickness and hardness of ST40 type steel," Proc. of the SNFT UMSIDA 2013, pp. 145-149, Sidoarjo, 2013. 
[10] S. Hadi, H. P. Buwono, and Subagiyo, "Copper electroplating on low carbon steel," Proc. of the SNTT 2018, State Polytechnic of Malang, vol. 4, pp. 17-24, Malang, 18-19 October 2018.

[11] S. S. M. Valeria, "Effect of temperature and time of electroplating process on corrosion resistance of black Chromium on Copper," Final Project RTP168002, D-IV Mech. Eng. Production and Maintenance Study Program, Department of Mech. Eng., State Polytechnic of Malang, pp. 1-58. 2020. 